\title{
Case study: effects of urban sustainable development on floods in the Grand Paris project
}

\author{
J. Anese ${ }^{1}$, P. Rigaudière ${ }^{1} \&$ M. Billard ${ }^{2}$ \\ ${ }^{1}$ Water Resources Business Unit, SAFEGE Consulting Engineers, France \\ ${ }^{2}$ Etablissement Public d'Aménagement Orly Rungis Seine Amont, France
}

\begin{abstract}
Grand Paris is a new global plan for the Paris metropolitan region; it has lead to a new transportation master plan and to development of several areas around Paris. Our case study is the project of national interest (Opération d'Intérêt National) by EPA ORSA (public institution of town planning Orly-RungisUpstream Seine river), located in the south-east of Paris suburbs, including Seine and Marne rivers. The urban sustainable development of this area should be finished in 2050, its aim is to "live with the river" but at the same time increase the resilience. We have created a 2D model (with TELEMAC 2D) of the EPA ORSA territory, and run several urbanization scenarios for different stages of the project $(2011,2018,2025$ and 2050) and ten flood events. The redevelopment of the Seine Valley has to respect the French Water Act and then cause zero impact. Also, we have built a 1D model (with HEC-RAS) to spread the water level and discharge impact in the Seine Valley (upstream and downstream of the 2D area). Through the "Grandes Ardoines", located in Vitry example, we can see that an urban sustainable development without hydraulic impact is possible.

Keywords: TELEMAC 2D, resilience, floods, Paris, sustainable development, hydraulic impact, town planning.
\end{abstract}

\section{Introduction}

The Orly Rungis - Seine Amont Operation of National Interest is placed under the responsibility of a Public Development Agency, or EPA ORSA [1]. This partner structure, created in 2007, oversees both the political governance and the strategic and operational engineering of this major project. The EPA ORSA is 
located right at the center of the local area, in Choisy-le-Roi, and it has some forty people performing two fundamental roles: The strategic management of the major development project and the associated partnership policies (economy, transport, housing, real estate, environment etc.). The focus is on the local area as a whole, and the governing members share a long-term vision, which the EPA ORSA has helped to define and develop. The implementation of urban development projects, whether they concern development planning (plans, guides, references, intensive development zones, etc.) or specific action plans (economic prospection, re-housing, etc.). Here, the EPA ORSA acts as an engineering consultancy for the municipality, a developer in the context of a development zone or, occasionally, as a property developer.

This 71 sq. $\mathrm{km}$ area is one of Greater Paris' [2, 3] most promising new developments. It is home to Paris' second largest international airport, Orly, which handles 26 million passengers per year (figure 1). A TGV station is set to open soon in the area, which will then be directly served by high speed rail. The Seine River passes through it from Ivry to Ablon, covering a $15 \mathrm{~km}$ stretch before joining the Marne Confluence in Alfortville. Major industry and rail companies occupying high potential sites are likely to transfer here in the near future. In late 2007, these attributes led to the launch of a major urban planning operation of national interest in this area of Val-de-Marne, which represents 12 municipalities, 335,000 inhabitants and 160,000 jobs. One of the main levers for the Orly Rungis-Seine Amont development project is rooted in the area's accessibility, which is set to be significantly improved by the Greater Paris Express transit network, thanks to which the area will gain seven new stations.

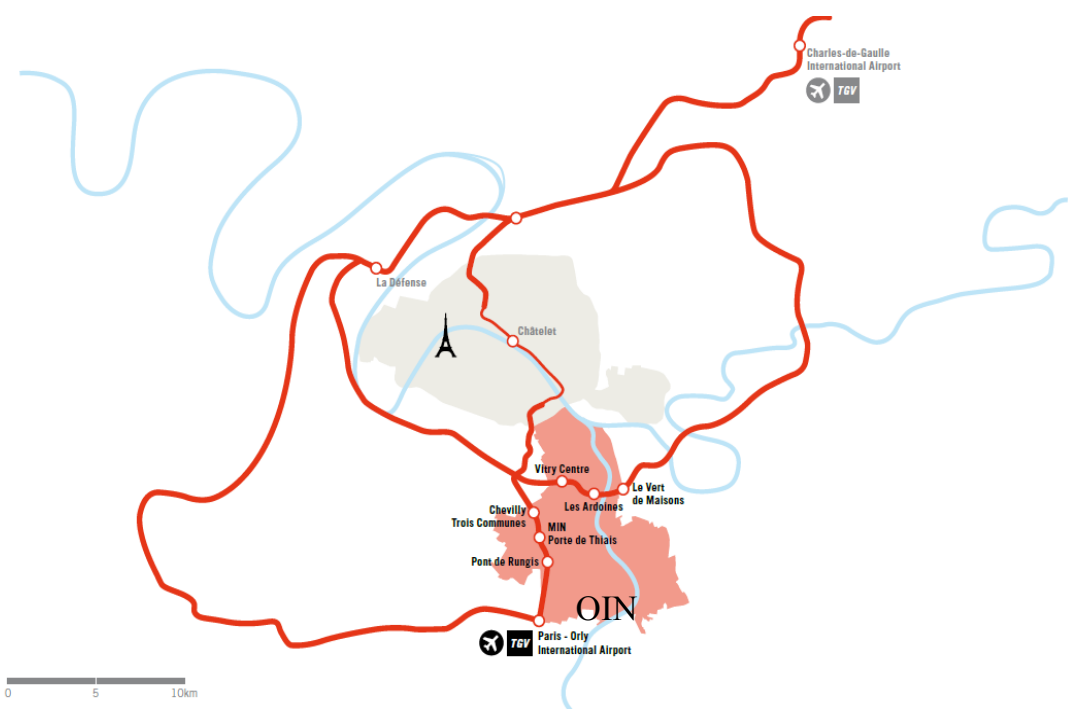

Figure 1: The Greater Paris Express transit lines will offer the area excellent connections to La Défense, Orly and Roissy airports and downtown Paris. 
At the moment EPA-ORSA is consolidating the "5 project areas", so far, no development hypothesis has been validated. The five project areas are (figure 2): - Les Grandes Ardoines (Vitry-sur-Seine city);

- Voeux (Orly city);

- Triage area (Villeneuve-Saint-Georges city);

- City Centre of Villeneuve-Saint-Georges;

- Ivry-Confluence project done by SADEV (Ivry-sur-Seine city).

In this article, we will just present the results for the project "Les Grandes Ardoines".

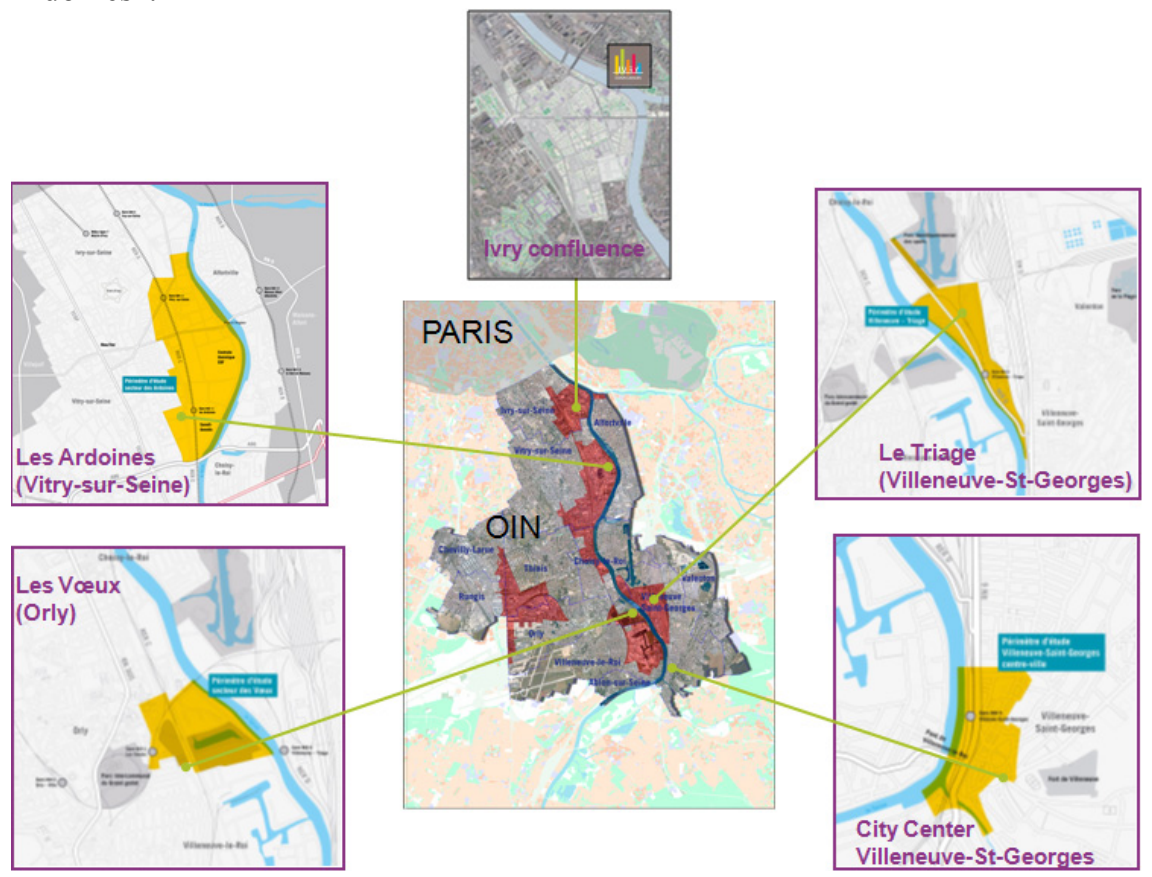

Figure 2: $\quad$ OIN and the 5 project areas.

Taking into account the territorial flooding possibility of these five project areas mentioned above is an essential part of the present EPA ORSA thinking over. Two major issues are the focus of these thoughts:

- How to plan these territories based on the observation that they are - and will largely remain - to the cause of flooding? A part of the answer consists in the implementation, at the first project step, of an approach aiming to reduce their vulnerability to flooding;

- How to respect the overall regulation of urban development in flood zones, in the case of complex operations on large, dense urban areas? The Water Act regulation guides this reflection, which shall include a double factor of space and time: what are the potential hydraulic impacts of different projects - local or regional, from the start to the end of their implementation? Do these projects respect the regulations? If not, what action shall be implemented to respect them? 
EPA ORSA engaged SAFEGE Engineering Consulting to perform a hydraulic study. The aim being to answer the issues mentioned above, the main objectives of this study are:

- Build a useful hydraulic model tool in order to understand the flooding process in the present and future development stages of the related territories;

- Identify and analyze the impacts of the urban planning, taking into consideration space and time factors;

- Establish some compensatory measures aiming no hydraulic impact of the urban planning and therefore respect the Water Act.

\section{Hydraulic model and hydrological scenario}

\subsection{Scales and models fitting}

From hydraulic point of view, we can consider two different study areas:

- OIN area, including 5 territories which are study in detail with a 2D model. This 2D approach will allow us to describe in detail the geometry of these five projects, and we will visualize the flow and its variables (depth and speed) as a two-dimension field, for the current and future situation.

- Larger area, the EPA ORSA projects can have hydraulic impact outside the OIN area described above. These impacts have to be analysed on a larger area, we spread them over the Marne and Seine branches $16 \mathrm{~km}$ upstream and $70 \mathrm{~km}$ downstream the OIN area.

The five territories will be completed in 2050, so in order to take in account the time scale; we will analyze the project hydraulic impact in 2011, 2018, 2025 and 2050 .

\subsection{The 2D hydraulic model}

The two-dimension hydraulic model in the OIN area is build with TELEMAC$2 \mathrm{D}$ module integrated into the TELEMAC modelling system. TELEMAC-2D is used to simulate free-surface flows in two dimensions of horizontal space $[4,5]$. At each point of the mesh, the program calculates the depth of water and the two velocity components. TELEMAC-2D solves the Saint-Venant equations using the finite-element or finite-volume method and a computation mesh of triangular elements. It can perform simulations in transient and permanent conditions.

The good quality DEM available on this area describes well all the roads, railways, embankments, etc. The 2D model of OIN area contains around 300,000 elements mesh (figure 3).

In order to represent the town-planning of the five territories, we modified the 2011 model changing the DEM and the roughness coefficient (Strickler coefficient).

The calibration of the model was difficult, indeed, the maximum discharge value during the flood in 1910 at Paris Austerlitz station is between 2400 and 


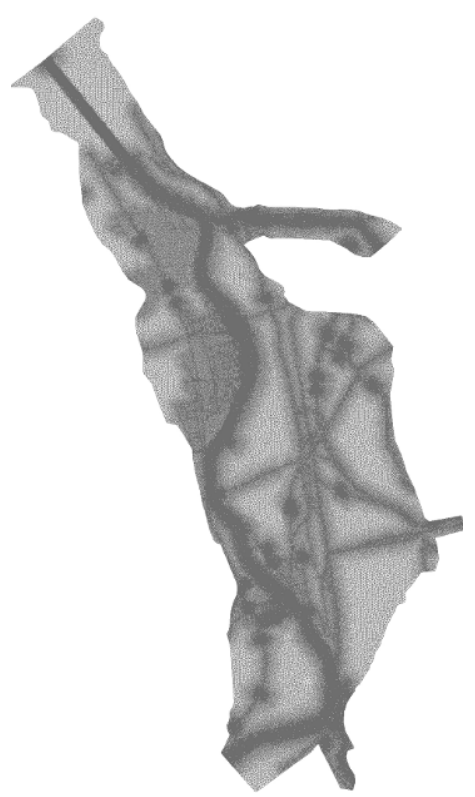

Figure 3: TELEMAC-2D model mesh for the 2011 situation.

$2660 \mathrm{~m}^{3} / \mathrm{s}$; also the conveyance in the Seine River and its floodplain has radically changed since hundred years. Nevertheless, we adjusted the Strickler coefficient to calibrate the model; we especially care to do a good calibration for not overflowing events at "Port à l'Anglais" and "Ablon" stations; we compared our calibration results to the one of a 1D model done by DIREN Ile-de-France in 2000 .

\subsection{D hydraulic model}

We built the 1D hydraulic model with HEC-RAS software [6], based on a simplified topography from a flood forecasting model used by SPC-DRIEE. This model (figure 4) includes the Seine and Marne rivers, all drainage structures (e.g. bridges and culverts). This model has been divided in three models: (1) Seine River upstream 2D model; (2) Marne River upstream 2D model; (3) Seine River downstream 2D model.

\subsection{Hydrological scenarios}

In order to illustrate the potential impacts of the different urban planning projects, a range of 10 hydrological scenarios has been defined:

- Frequent floods that may cause some problems in upstream part of Val de Marne department: 5, 10 or 20-year return period event: between 1500 and $1800 \mathrm{~m}^{3} / \mathrm{s}$ at Austerlitz bridge; 


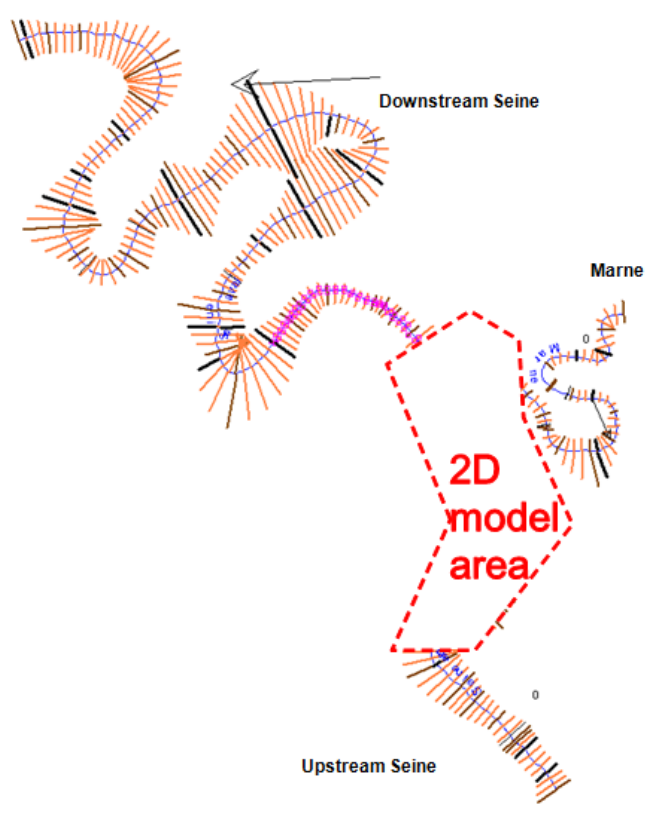

Figure 4: $\quad$ 1D HEC-RAS model.

- Intermediate events flooding a large part of the floodplain like events which happened in 1924 and 1955: between 2000 and $2200 \mathrm{~m}^{3} / \mathrm{s}$ at Austerlitz bridge;

- Major floods occupying most of the floodplain, this happened in 1910 which is the flood of reference: between 2400 and $2650 \mathrm{~m}^{3} / \mathrm{s}$ at Austerlitz bridge;

- Exceptional floods higher than those of $1910\left(2800 \mathrm{~m}^{3} / \mathrm{s}\right.$ at Austerlitz bridge), in order to respect the directive 2007/60/EC of the European Parliament on the assessment and management of flood risks for low return period event [7].

In total, we had 40 simulations:

- 10 runs for the 2011 situation;

- 10 runs for the 2018 situation, and comparison with the 2011 situation;

- 10 runs for the 2025 situation, and comparison with the 2011 situation;

- 10 runs for the 2050 situation, and comparison with the 2011 situation.

\section{3 "Les Grandes Ardoines" project hypothesis}

\section{1 "Les Ardoines" project description}

Les Grandes Ardoines is a 300-hectare site (figures 5 and 6). This is one of the most promising developments in Greater Paris [8]. With an exceptional location 
overlooking the Seine, easy access and a thriving economy based primarily on industrial activities, the zone will be totally transformed to become a key feature of the metropolitan area. The site aims to develop 13,000 housing units and attract 45,000 jobs.

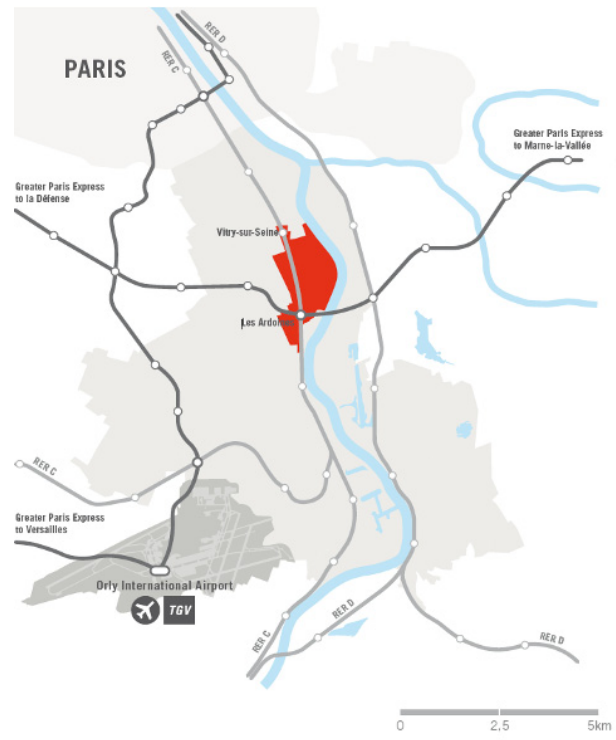

Figure 5: "Les Grandes Ardoines" project location.

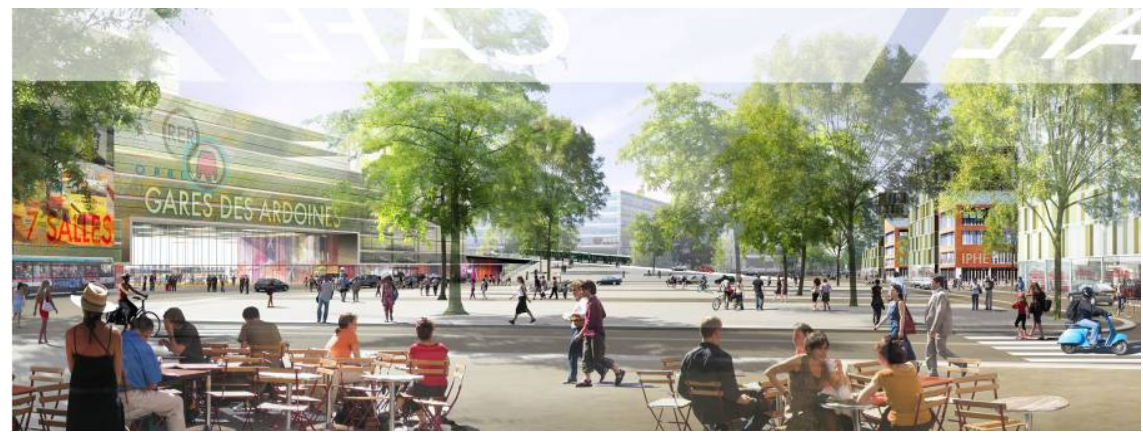

Figure 6: "Les Grandes Ardoines" (source: SEURA).

\section{2 “Les Grandes Ardoines" project description}

The redevelopment project in "Les Ardoines" will also be the occasion to create new public spaces, to redesign the banks of the Seine as a park, and to build housing with nearby shops, services and amenities. The sector expects to see a population of 25,000 inhabitants.

The business activities in "Les Ardoines" - currently counting 400 companies and 9,000 jobs - will be enhanced. A biotech zone, created in proximity to 
Sanofi-Aventis (a world leader in pharmaceuticals), will make Les Ardoines a pillar of the Paris area's bio-cluster. It will offer specialized premises for research, production and service activities in the field of biotechnologies and will include a start-up park and business incubator for biotech projects in a building devoted to the knowledge economy. Offices will be built for the service sector and other activities, while reserving sites to support the construction industry, wholesale and logistics operations. Small and medium-sized businesses will thrive, especially in the region's fields of expertise: mechatronics and aeronautics, agribusiness, green enterprises, materials, imaging.

So far, the guide plan of the urban project was designed by David Mangin in 2011 (SEURA). With the beginning of construction foreseen in 2014/2015, this plan is being consolidated considering technical and financial issues. Elements shown below must be taken as a work in progress being matured from now.

From hydraulic point of view, the future area should gradually receive the flood and let the water enter the area, and then part of the living space should be above an event being 1,15 times more important than the 1910 flood level: around $36 \mathrm{mNGF}$ in this area. The resilience flood approach includes, at terms, as it is defined in the guide plan of 2011:

- Bank lowered so that it will be flooded by frequent floods and participate to risk culture for inhabitants;

- An area whose level of protection is enhanced of a few decimeters to $34 \mathrm{mNGF}$ so that this area is protected for 1924 flood event. Building are enhanced over the 1910 flood so that goods and persons are protected in case of that case of flood in accordance with PPRI ((Plan de Prévention au Risque d'Inondation): Flood Risks Prevention Act edicted in 2000 in Val-de-Marne then overhauled in 2007);

- Proximate to railways, an area is set at a level of protection able to resist a flood 1,15 times worse than the 1910 flood;

- A new bridge over the Seine River headed for Alfortville;

- Exchanges between both sides of the railway are done with another bridge above the railway.

Figure 8 describes the steps of the project development:

\subsection{Local impact analysis}

The hydraulic impact analysis caused by the Ardoines urban development is complex, the effects can be very different regarding the project stage.

The Ardoines area is and will be vulnerable to floods from a 1924 flood event $\left(2200 \mathrm{~m}^{3} / \mathrm{s}\right.$ at Austerlitz Bridge). Overflows will happen more often from a 5 -year return period event $\left(1450 \mathrm{~m}^{3} / \mathrm{s}\right.$ at Austerlitz Bridge) because the left bank development allows for receiving more water.

During flood events bigger than 1924 event, a general overflow happens in south of Val-de-Marne department.

We could imagine that the Ardoines central part development hypothesis will cause important hydraulic impact, but the model results show a small impact because the main flow direction South-North is not modified. 


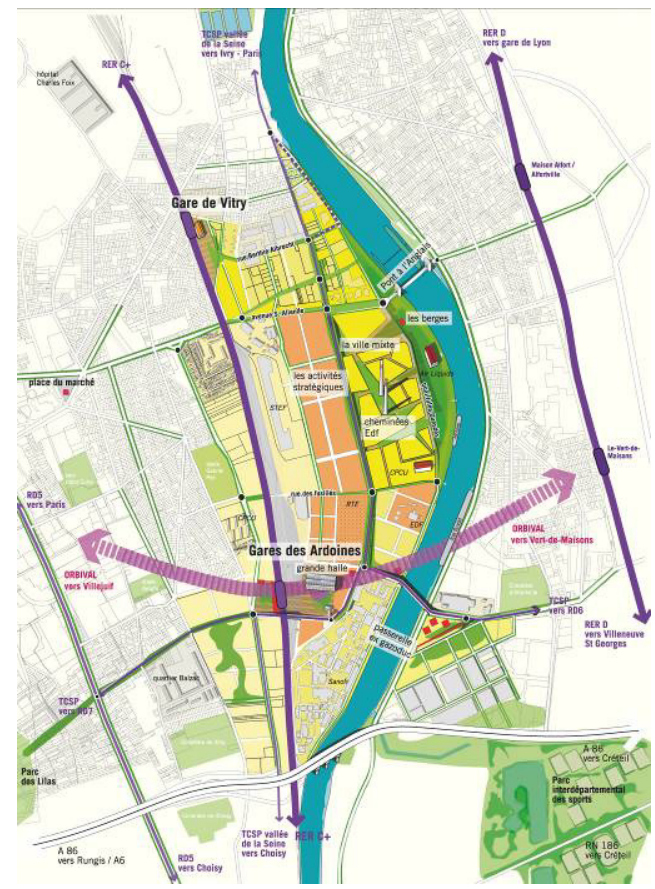

Figure 7: Description of projected levels of protection as defined by the guide plan of 2011 (source: SEURA).

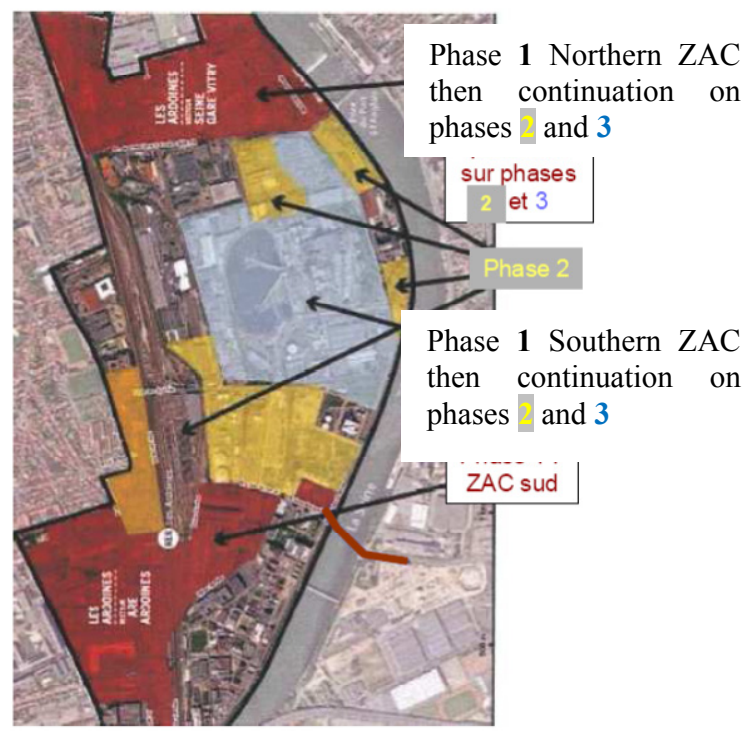

Figure 8: $\quad$ Steps of the project development. 


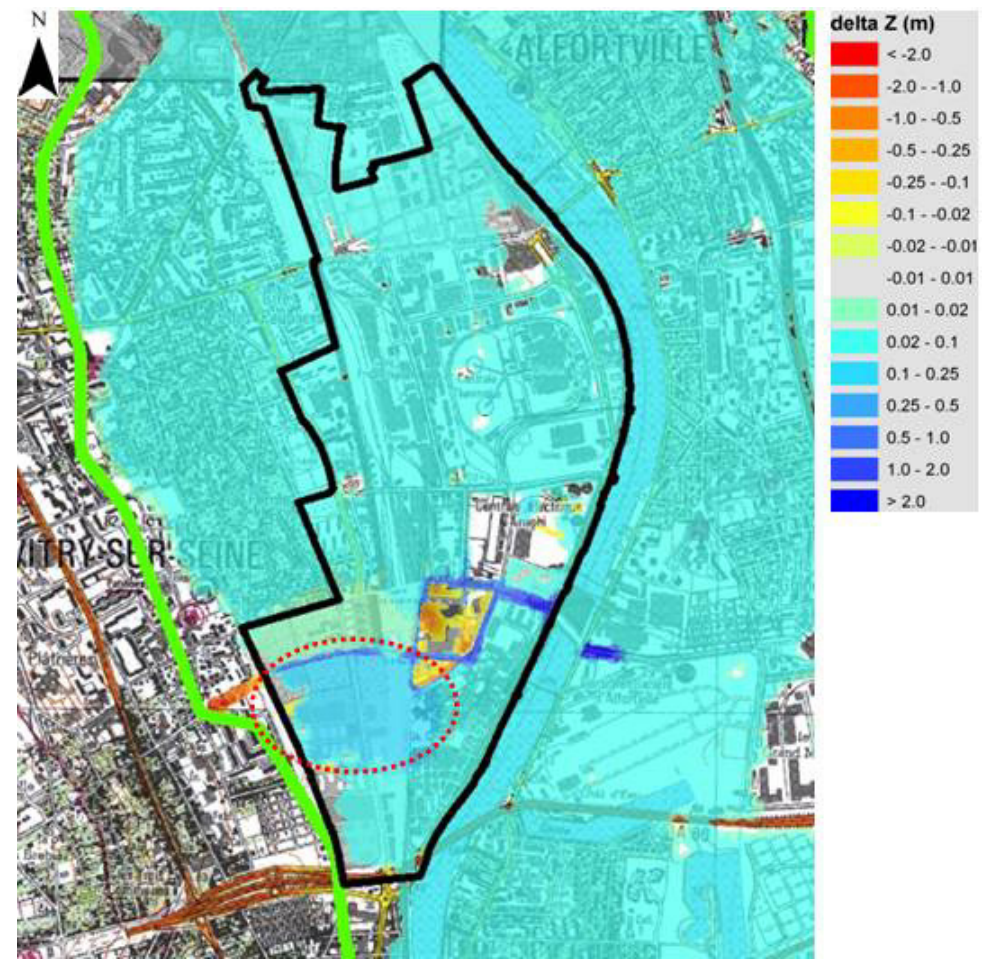

Figure 9: Water level impact for 1910 flood event, Ardoines project 2018 stage.

The simulation for the 2018 situation shows the highest hydraulic impact (figure 9); this is because the East-West railways overpass East-West, the left bank changes are not done in 2018. We can notice that the left bank development will compensate the hydraulic impact of the East-West overpass. Nevertheless, for the 2018 stage we need to find some ways to solve this hydraulic impact problem in order to respect the French Water Act that implies zero hydraulic impact on each step of development (unit of space and time).

\subsection{Zero impact measures}

SAFEGE and EPA ORSA meet several times DRIEE (Water Police) in order to discuss and be sure to respect the French Water Act. For each stage of each project there should be no hydraulic impact. The results of the solutions discussed in the previous chapter being not satisfying, SAFEGE and EPA ORSA had to find some ways to reduce the hydraulic impact.

We run a scenario with only the Ardoines project in the 2018 stage (the other project are in the 2011 situation) for a 1910 flood event.

In order to aim for a zero impact, we have proposed some changes: the overpass should be more transparent and let the South-North flow (figure 10). 


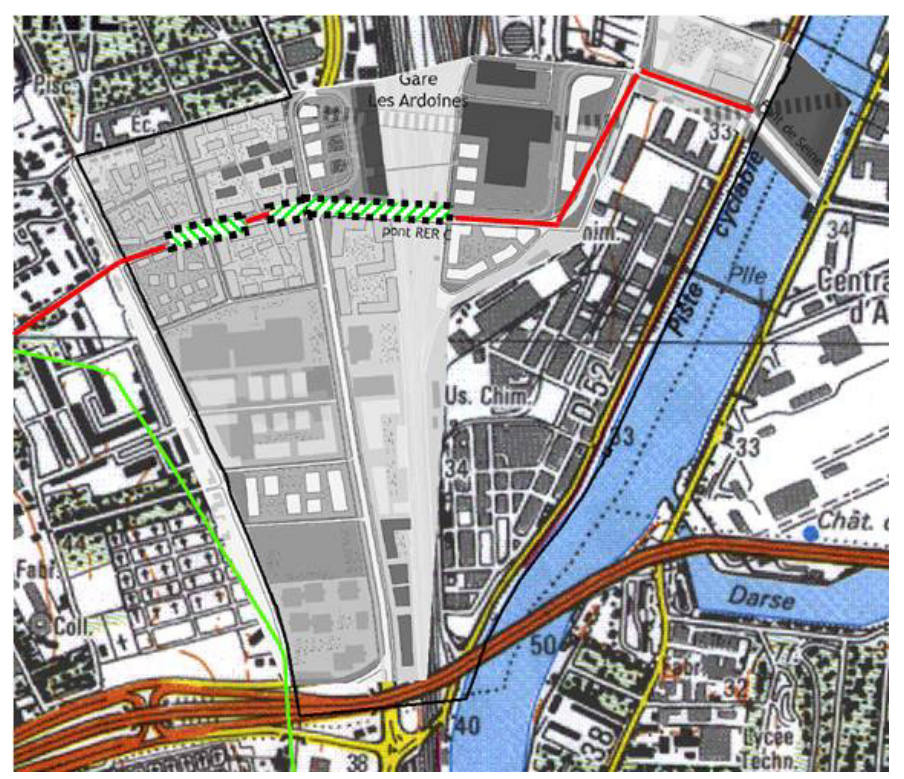

Figure 10: New opening (green) in order to have a more transparent overpass.

As we can see (figure 11), these measures solved the problems; there is no more impact south of the overpass, the flow goes easier to the North.

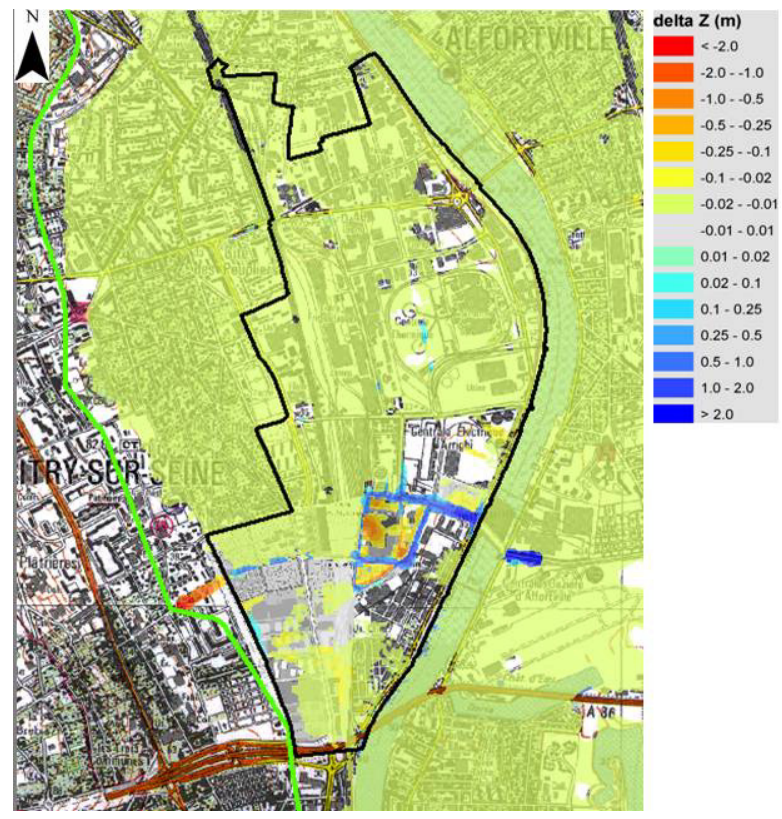

Figure 11: Water level impact reduced for 1910 flood event, Ardoines project 2018 stage. 


\subsection{Global impact analysis}

In the previous chapter, we saw that the hydraulic impact almost disappeared for the simulation 2018 with the 1910 flood event. At the 2D upstream boundary, the water level difference is $-1 \mathrm{~cm}$; at the $2 \mathrm{D}$ downstream boundary, the discharge difference is $-3.9 \mathrm{~m}^{3} / \mathrm{s}$. We can illustrate how this impact spread downstream and upstream of the 2D area on the Seine River, for that the 1D HEC-RAS model was used.

We found that the impact on water level and discharge does not change over $70 \mathrm{~km}$ downstream, and $16 \mathrm{~km}$ upstream the OIN area.

\section{Conclusion}

In this study, a 2D model was built to represent a hypothesis urban development and a 1D model to spread the water level and discharge impact. We could see that a small water impact can spread over $70 \mathrm{~km}$, so it's important to care the volume budget during flood event for an urban development. Through this example, "Les Grandes Ardoines" hypothetic project, SAFEGE and EPA ORSA success to find some solutions to implement urban sustainable development without hydraulic impact, and then respect the French Water Act.

\section{References}

[1] Établissement Public d'Aménagement Orly Rungis Seine Amont, EPA ORSA, Projet Stratégique Directeur, pp. 1-58, 2009.

[2] Lemoine, B., Douze clefs de lecture pour comprendre le Grand Paris, Atelier International du Grand Paris : Paris, 2012.

[3] Atelier International du Grand Paris. La consultation du Grand Paris de 2008, http:/www.ateliergrandparis.com/aigp/conseil/consultation2008.php

[4] Hervouet, J.M., Hydrodynamique des écoulements à surface libre. Modélisation numérique avec la méthode des éléments finis, Presses de l'École nationale des ponts et chaussées : Paris, 2003.

[5] Hervouet, J.M. and Bates, P., The TELEMAC modelling system Special issue. Hydrological Processes, 14(13), 2000.

[6] Brunner, G.W., HEC-RAS River analysis system. Hydraulic reference manual. Version 4.1, US Army Corps of Engineers. Hydrologic Engineering Center: Davis, 2010.

[7] European Parliament and European Council, Directive 2007/60/EC of the European Parliament and of the Council of 23 October 2007 on the assessment and management of flood risks, Official Journal of the European Union, L 288, 6.11.2007, pp. 27-34.

[8] Établissement Public d'Aménagement Orly Rungis Seine Amont, EPA ORSA, Les Ardoines à Vitry-sur-Seine, L'essor d'un projet métropolitain, pp. 1-36, 2009. 